\title{
Single systemic administration of Ag85B of mycobacteria DNA inhibits allergic airway inflammation in a mouse model of asthma
}

\section{Katsuo Karamatsu',2 \\ Kazuhiro Matsuo ${ }^{3}$ \\ Hiroyasu Inada ${ }^{4}$ \\ Yusuke Tsujimura' \\ Yumiko Shiogama ${ }^{1,2}$ \\ Akihiro Matsubara ${ }^{1,2}$ \\ Mitsuo Kawano 5 \\ Yasuhiro Yasutomi ${ }^{1,2}$}

'Laboratory of Immunoregulation and Vaccine Research, Tsukuba Primate

Research Center, National Institute of Biomedical Innovation, Tsukuba,

${ }^{2}$ Division of Immunoregulation,

Department of Molecular and

Experimental Medicine, Mie University

Graduate School of Medicine,

Tsu, ${ }^{3}$ Department of Research and

Development, Japan BCG Laboratory,

Tokyo, ${ }^{4}$ Department of Pathology,

Suzuka University of Medical

Science, Suzuka, ${ }^{5}$ Department of

Microbiology and Molecular Genetics, Mie University Graduate School of

Medicine, Tsu, Japan
This article was published in the following Dove Press journal:

Journal of Asthma and Allergy

30 November 2012

Number of times this article has been viewed

\begin{abstract}
The immune responses of T-helper (Th) and T-regulatory cells are thought to play a crucial role in the pathogenesis of allergic airway inflammation observed in asthma. The correction of immune response by these cells should be considered in the prevention and treatment of asthma. Native antigen $85 \mathrm{~B}$ (Ag85B) of mycobacteria, which cross-reacts among mycobacteria species, may play an important biological role in host-pathogen interaction since it elicits various immune responses by activation of Th cells. The current study investigated the antiallergic inflammatory effects of DNA administration of Ag85B from Mycobacterium kansasii in a mouse model of asthma. Immunization of BALB/c mice with alum-adsorbed ovalbumin followed by aspiration with aerosolized ovalbumin resulted in the development of allergic airway inflammation. Administration of Ag85B DNA before the aerosolized ovalbumin challenge protected the mice from subsequent induction of allergic airway inflammation. Serum and bronchoalveolar lavage immunoglobulin E levels, extent of eosinophil infiltration, and levels of Th2-type cytokines in Ag85B DNA-administered mice were significantly lower than those in control plasmid-immunized mice, and levels of Th1- and T-regulatory-type cytokines were enhanced by Ag85B administration. The results of this study provide evidence for the potential utility of Ag85B DNA inoculation as a novel approach for the treatment of asthma.
\end{abstract}

Keywords: immunotherapy, asthma, Ag85B, mycobacteria, allergy

\section{Introduction}

Asthma is characterized by airway hyperresponsiveness to a variety of specific and nonspecific stimuli, chronic pulmonary inflammation with eosinophilia, excessive mucus production, and high serum immunoglobulin E (IgE) levels. T-helper-2 (Th2) cells are thought to play a crucial role in the initiation, progression, and persistence of asthma in association with the production of interleukin-4 (IL-4), IL-5, and IL-13. ${ }^{1-3}$ Bronchoalveolar lavage (BAL) T-cells from human asthmatics have been reported to express elevated levels of IL-4 and IL-5 messenger ribonucleic acid (mRNA).,5 Although the correction of this deviation to Th2-type immune responses is considered to be necessary to achieve therapeutic and preventive effects on asthma, it is not sufficient to obtain therapeutic effects in many cases. Another subset of T-cells, T-regulatory (Treg) cells, has been reported to be important in the development of allergic diseases such as asthma. ${ }^{6}$ Many studies have suggested that effective immunotherapy for allergic diseases is associated with immune deviation from a disease-promoting $\mathrm{Th} 2$ response towards a Th1 response, with Treg cells having appropriate functions. ${ }^{7}$ However, the induction of both subsets of cells - Th1 and Treg cells - for the treatment of asthma using immunological strategic tools is very difficult.
Correspondence: Yasuhiro Yasutomi Laboratory of Immunoregulation and Vaccine Research, Tsukuba Primate Research Center, National Institute of Biomedical Innovation, I-I Hachimandai, Tsukuba, Ibaraki 305-0843, Japan

Tel +8I 298372053

Fax +8I 298372053

Email yasutomi@nibio.go.jp 
Administration of mycobacteria, including the bacillus Calmette-Guerin, has been thought to be effective for preventing the development of asthma by induction of Th1-type immune responses and inhibition of IgE by the production of IL-21 from natural killer T-cells..$^{8-10}$ However, the relationship between bacillus Calmette-Guerin infection or mycobacteria immunization and asthma in humans is controversial because of the many causative factors affecting the induction of immune responses by mycobacteria, eg, human genetic background, mycobacteria strains, and environmental factors (reviewed in Arnoldussen et al). ${ }^{11}$ From these findings, bacterial products from mycobacteria for immunotherapy against allergic disease should eliminate the harmful effects of host genetic factors, environmental factors, and strain specificity of mycobacteria.

Antigen 85B (Ag85B) is one of the most dominant protein antigens secreted from all mycobacterial species and has been shown to induce substantial Th cell proliferation and vigorous Th1 cytokine production. ${ }^{12}$ Moreover, the induction of Th1-type immune responses by immunization of Ag85B was enhanced by presensitization with bacillus CalmetteGuerin. ${ }^{13,14}$ From these findings, the effectiveness of Ag85B DNA as immunotherapy for tumor disease and as a vaccine adjuvant for infectious disease, by its ability to induce Th1type immune responses, was also reported. ${ }^{13,14}$ The current study investigated whether Ag85B DNA from Mycobacterium kansasii can inhibit the development of allergic airway inflammation as a novel immunotherapy.

\section{Material and methods} Induction of allergic inflammation in mice $\mathrm{BALB} / \mathrm{c}$ female mice used in this study were handled according to ethical guidelines approved by the Institutional Animal Care and Use Committee of National Institute of Biomedical Innovation, Japan. The mice were sensitized to ovalbumin (OVA; Sigma-Aldrich, St Louis, MO) and challenged with aerosolized OVA according to a modification of the method of Nishikubo et al. ${ }^{15}$ Briefly, mice were subcutaneously immunized with $10 \mu \mathrm{g}$ OVA complexed with alum on days zero and 14 . On days 21-25 after the first immunization, mice were challenged with an aerosol of 5\% OVA in phosphatebuffered saline in a chamber for 20 minutes.

\section{Administration of DNA}

Mice were intraperitoneally administered $50 \mu \mathrm{g}$ plasmid DNA encoding Ag85B DNA once on day -7, zero, 14, or 21. An empty plasmid vector (pcDNA ${ }^{\mathrm{TM}} 3.1$; Life Technologies, Carlsbad, CA) was used as a control (Figure 1A).

\section{BAL fluid collection}

BAL fluid was obtained by injecting and recovering two $0.5 \mathrm{~mL}$ aliquots of phosphate-buffered saline via a tracheal cannula. BAL fluid and sera were collected 25 days after the first OVA immunization. Cells in the BAL fluid were counted using a hematocytometer, and the differentials were determined by utilizing light microscopy to count 300 cells on Cytospin ${ }^{\circledR}$ preparations (Thermo Fisher Scientific, Waltham, MA). The concentration of inflammatory protein was measured by Protein Assay Reagent (Bio-Rad Laboratories, Hercules, CA).

\section{Quantitation of $\lg E$}

IgE levels in sera were measured using enzyme-linked immunosorbent assay (ELISA) kits according to the procedure recommended by the manufacturer (Shibayagi Co, Ltd, Shibukawa, Japan).

\section{Determination of cytokine production}

Lymphocytes obtained from thoracic lymph nodes of immunized mice $\left(5 \times 10^{6}\right)$ were cultured with $10 \mu \mathrm{g} / \mathrm{mL}$ OVA in 24-well culture plates at a volume of $2 \mathrm{~mL}$. After incubation at $37^{\circ} \mathrm{C}$ in a humidified incubator (5\% carbon dioxide) for 48 hours, culture supernatants were collected and analyzed for production of interferon- $\gamma$ (IFN- $\gamma$; Life Technologies) or IL-4 (Quantikine ${ }^{\circledR} ;$ R\&D Systems, Minneapolis, MN) by an ELISA assay according to the manufacturer's protocol (Life Technologies). The amounts of IL-5 and IL-13 in BAL fluid were also measured by an ELISA kit (R\&D Systems) 25 days after the first OVA immunization.

\section{Detection of cytokine mRNA from lymphocytes using real-time polymerase chain reaction}

Total RNA was purified from OVA-stimulated or fetal calf serum (control)-stimulated spleen cells using Isogen (Nippon Gene Co, Ltd, Tokyo, Japan) following the manufacturer's instructions. For the real-time reaction, a reverse transcription system (Promega Corporation, Fitchburg, WI) was used. Polymerase chain reaction was performed in a total volume of $50 \mu \mathrm{L}$ of $1 \times$ polymerase chain reaction buffer (Takara Shuzo, Kyoto, Japan) containing $0.5-1.0 \mu \mathrm{g}$ of complementary DNA, $0.25 \mathrm{mM}$ of each deoxyribonucleotide triphosphate, $2 \mu \mathrm{M}$ of each primer, and $2.5 \mathrm{U}$ of Taq DNA polymerase (Takara Shuzo). The specific primer pairs used were described previously. ${ }^{15}$ The samples were amplified for 30-35 cycles under the following conditions: annealing for 30 seconds at $56^{\circ} \mathrm{C}$, extension for 1 minute at $73^{\circ} \mathrm{C}$, and denaturation for 30 seconds at $93^{\circ} \mathrm{C}$. The reaction products were 
A

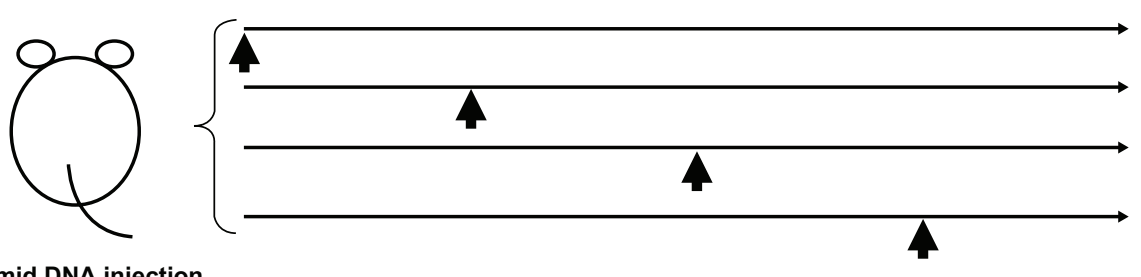

4 Plasmid DNA injection

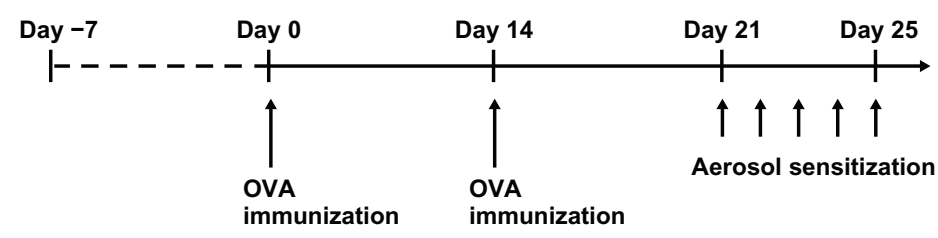

B
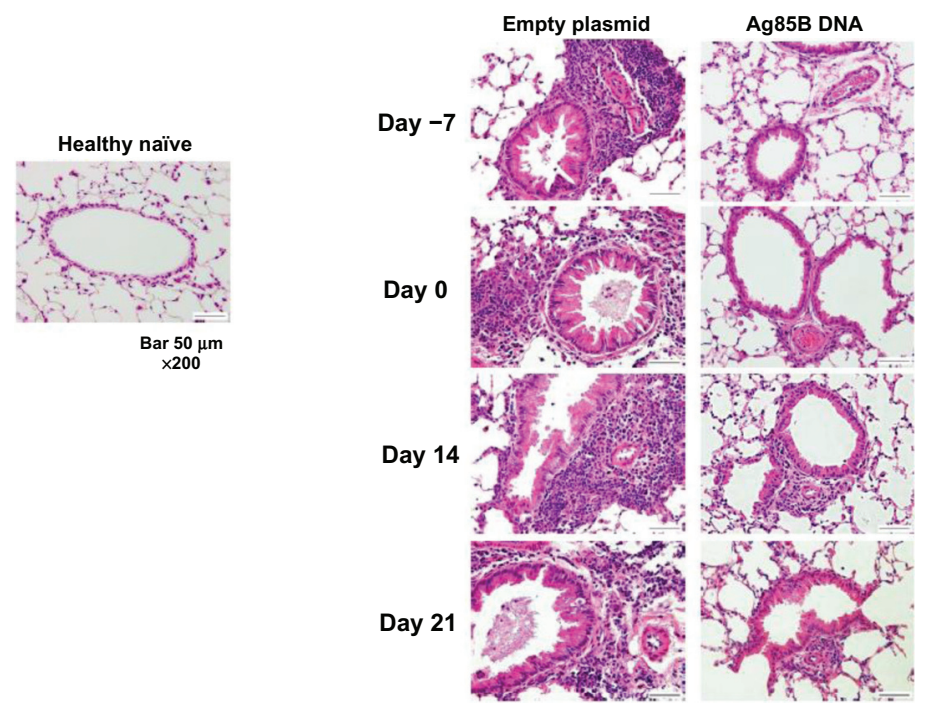

Figure I Inhibition of the development of allergic inflammation in lungs by administration of Ag85B DNA vaccine. (A) Experimental design used to investigate the effects of Ag85B DNA vaccine on OVA-induced asthma. Mice were subjected to an OVA sensitization scheme, ${ }^{15}$ and $50 \mu g$ of Ag85B DNA vaccine was intraperitoneally injected once on days $-7,0,14$, or 21 . A control plasmid was also administered on the same day. (B) Results of histopathological examination of lungs of mice that had been administered Ag85B DNA or control DNA. All tissues were obtained 25 days after the first OVA immunization. The tissues were fixed in $10 \%$ formalin, embedded in paraffin, sectioned, and stained with hematoxylin and eosin.

Abbreviations: Ag85B, antigen 85B; OVA, ovalbumin.

analyzed on 2\% agarose, Tris-buffered ethylenediaminetetraacetic acid gel. Photographs of the gels were scanned, and band intensities were measured using a densitometer (CS Analyzer 3.0; ATTO Corporation, Tokyo, Japan). The quantity of cytokine mRNA was determined by the ratio of cytokine and beta actin band intensities. The profiles shown are representative of three independent experiments.

\section{Histopathological examinations}

Histopathological examinations of the lungs of the mice that had been administered Ag85B DNA or control DNA were performed. All tissues were obtained 25 days after the first OVA immunization. The tissues were fixed in $10 \%$ formalin, embedded in paraffin, sectioned, and stained with hematoxylin and eosin. Results for healthy naïve mice and control plasmid DNA-immunized mice are also shown.

\section{Statistical analysis}

Statistical analyses were performed using the Mann-Whitney U test and the Kruskal-Wallis test. Values are expressed as mean \pm standard deviation. A $95 \%$ confidence limit was considered to be significant $(P<0.05)$.

\section{Results}

\section{Inhibition of the development of allergic inflammation in the lung by administration of Ag85B DNA}

Mice were sensitized to OVA and challenged with aerosolized OVA as described previously. ${ }^{11}$ These mice were intraperitoneally administered $50 \mu \mathrm{g}$ plasmid DNA encoding Ag85B once on day -7 , zero, 14, or 21. An empty plasmid vector (pcDNA 3.1) was used as a control (Figure 1A). 
Histopathological examinations of the lungs of mice injected with Ag85B DNA or control DNA and the lungs of healthy naïve mice were performed 25 days after the first inoculation of the plasmid. The lungs of mice that were administered Ag85B DNA on days -7 , zero, and 14 did not show any pathological abnormalities compared with those of healthy naïve mice, but the lungs of mice that were administered Ag85B DNA on day 21 showed mild inflammation due to infiltration of eosinophils (Figure 1B). Mice administered the control plasmid did not show any inhibitory effects on the development of allergic inflammations. These results indicated that Ag85B DNA administration was effective for inhibiting the development of allergic inflammation, especially in the early phase of antigen sensitization.

\section{Marked inhibition of allergic immune responses by administration of Ag85B DNA}

The levels of protein, total cells, eosinophils, lymphocytes, and neutrophils in BAL fluid from mice immunized with Ag85B DNA vaccine were significantly lower than those in BAL fluid from mice vaccinated with control DNA (Figure 2A-F). Administration of Ag85B DNA also resulted in a significant reduction in the level of OVA-specific IgE (Figure 2G). The concentrations of Th2-type cytokines (IL-5 and IL-13) in BAL fluid from mice immunized with Ag85B DNA vaccine were significantly lower than those in BAL fluid from control mice (Figure 3A and B). These inhibitory effects on the development of allergic inflammation were correlated with day of Ag85B DNA injection. Injection on an early day was more effective for inhibiting the development of allergic inflammation. These results were also confirmed by histopathological observation.

\section{Effects of Ag85B DNA administration on the production of IL-4 and IFN- $\gamma$ in response to OVA}

The production of OVA-specific cytokines in lymph node cells after in vitro stimulation with OVA were assessed. The lymphocytes obtained from thoracic lymph nodes were stimulated in vitro with OVA for 48 hours. IL-4 and IFN- $\gamma$ levels were measured in culture supernatants by ELISA. The level of IL-4 in culture supernatants from cells of Ag85B DNA-immunized mice was much lower than in culture supernatants from cells of control mice (Figure 4A). On the other hand, the production level of IFN- $\gamma$ in Ag85B DNAimmunized mice was significantly higher than in control DNA-immunized mice (Figure 4B).

\section{Expression of cytokine mRNA in pulmonary lymph node cells after stimulation with OVA}

The production of OVA-specific cytokines was also confirmed by mRNA levels of Th1-type cytokines (IFN- $\gamma$, IL-2, and IL-12) and Th2-type cytokines (IL-4, IL-5, and IL-13) (Figure 5A-C). Lymph node cells from Ag85B DNA vaccine-immunized mice showed strong IFN- $\gamma$, IL-2, and IL-12 expression and weak IL-4, IL-5, and IL-13 expression of mRNA, whereas control DNA-immunized mice showed the completely opposite results. The cells from control mice showed strong mRNA expression of Th2-type cytokines and weak mRNA expression of Th1-type cytokines (Figure 5A-C). It has been reported that therapeutic effects against asthma by administration of the culture supernatant of $M$. vaccae were derived from Treg cells by the induction of IL-10 and transforming growth factor- $\beta .{ }^{16}$ In the current study, mRNA expression levels of IL-10 and transforming growth factor- $\beta$ in lymph node cells obtained from mice immunized with Ag85B DNA were much higher than those in lymph node cells obtained from control mice after in vitro stimulation with OVA (Figure 5A and D). Another Th17 cell lineage, which is associated with allergen-induced airway allergic inflammation, was also assessed by the mRNA expression of cytokines. In the current experiment, mRNA expression of IL-17 was seen in both control DNA-immunized and Ag85B-DNA immunized mice after stimulation with OVA, with no difference in the mRNA expression levels of IL-17 between these groups (Figure 5A and E). The mRNA expression of IL-23 was also assessed since IL-23 is associated with the maturation of Th17 cells. ${ }^{17}$ Expression of IL-23 mRNA was observed at the same level in all samples (Figure 5A and E). Inhibitory effects on the development of allergic inflammation are readily obtained in a mouse model of asthma through the administration of Ag85B DNA. These effects of immunotherapy by Ag85B DNA are due to activation of the immune responses of Th1 and Treg cells and inhibition of the responses of Th2 cells as a result of the enhancement of responses of Th1 and Treg cells.

\section{Discussion}

Current treatments of nonspecific immunosuppressive therapy for asthma, such as administration of glucocorticoids, are not satisfactory. Although these treatments are highly effective for controlling disease, most patients must continue to take these drugs throughout their lives. Moreover, these drugs have side effects, and asthma cannot be controlled by these drugs in up to $30 \%$ of patients. Given the high prevalence 

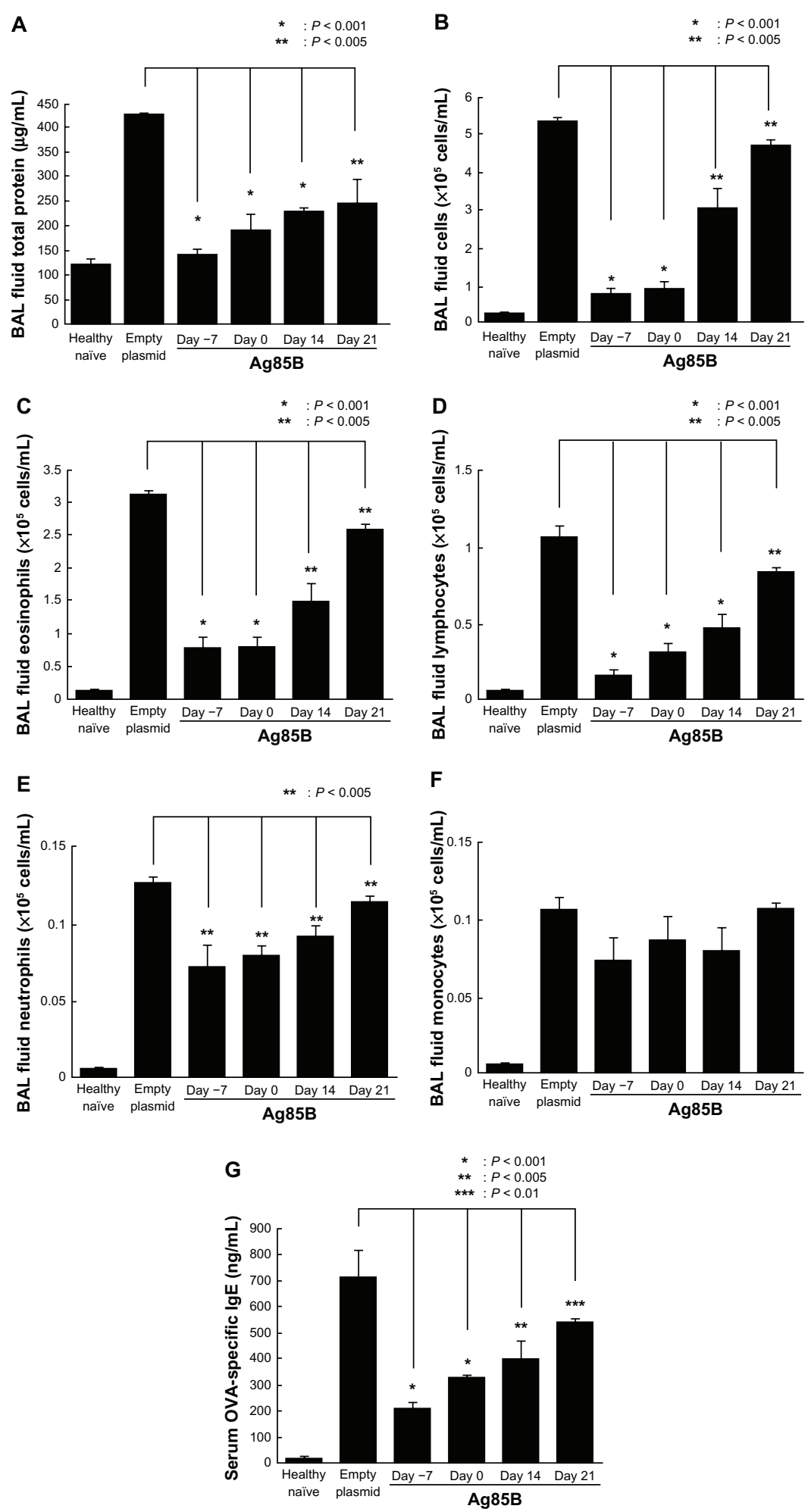

Figure 2 Marked inhibition of the development of allergic inflammation by administration of Ag85B DNA. BAL fluid was obtained by injecting and recovering two $0.5 \mathrm{~mL}$ aliquots of phosphate-buffered saline via a tracheal cannula. Cells in the lavage fluid were counted using a hematocytometer, and the differentials were determined by utilizing light microscopy to count 300 cells on Cytospin ${ }^{\circledR}$ preparations (Thermo Fisher Scientific, Waltham, MA). The concentration of inflammatory protein was measured by Protein Assay Reagent (Bio-Rad Laboratories, Hercules, CA). Results for healthy naïve mice and control plasmid DNA-immunized mice are also shown. (A) Total protein, (B) number of cells, (C) eosinophils, (D) lymphocytes, (E) neutrophils, and (F) monocytes in BAL fluid from experimental animals were investigated. (G) The degrees of ovalbumin-specific immunoglobulin E responses in sera collected from experimental mice were also analyzed. Immunoglobulin E levels in sera were measured using enzyme-linked immunosorbent assay kits according to the procedure recommended by the manufacturer (Shibayagi Co, Ltd, Shibukawa, Japan). BAL fluid and sera were collected 25 days after the first ovalbumin immunization. Notes: Data are representative of at least three independent experiments; values shown are the means and standard deviations of five mice per group; statistical analysis was performed using the Mann-Whitney $U$ test and the Kruskal-Wallis test.

Abbreviations: Ag85B, antigen 85B; BAL, bronchoalveolar lavage. 

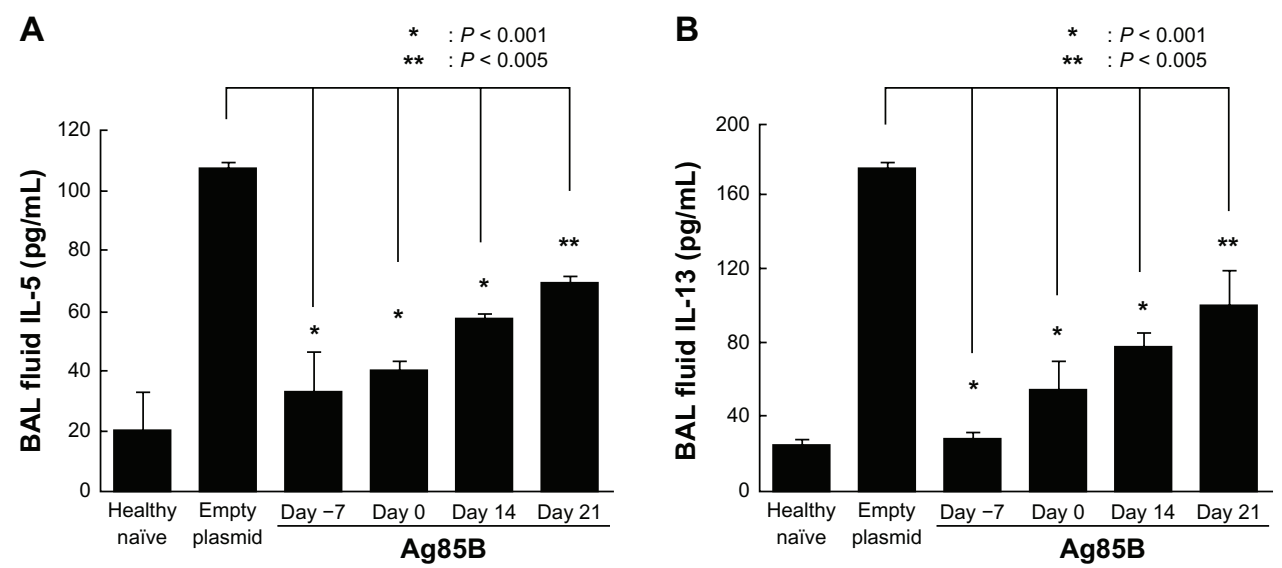

Figure 3 IL-5 and IL-I3 production in BAL fluid. Amounts of (A) IL-5 and (B) IL-I3 in BAL fluid were measured using an enzyme-linked immunosorbent assay kit (R\&D Systems, Minneapolis, MN) 25 days after the first ovalbumin immunization.

Notes: Data are representative of at least three independent experiments; values shown are means and standard deviations of five mice per group; statistical analysis was performed using the Mann-Whitney $U$ test and the Kruskal-Wallis test.

Abbreviations: Ag85B, antigen 85B; BAL, bronchoalveolar lavage; IL, interleukin.

of this disease, improved and more effective therapeutic strategies are needed. The results of many studies have suggested that effective immunotherapy for allergic disease is associated with immune deviation from a disease-promoting Th2 response towards a Th1 response, with Treg cells having appropriate functions (reviewed in Takeda et al). ${ }^{18} \mathrm{In}$ the current study, the applicability of plasmid encoding complementary DNA of Ag85B from mycobacteria DNA to gene therapy of asthma was assessed. Although the introduced DNA is expressed predominantly by somatic cells, it is known that a relatively small but biologically significant number of dendritic cells are transfected with the inoculated DNA. ${ }^{19-21}$ Moreover, it was recently reported that systemic inoculation of a plasmid DNA may cause dendritic cell activation through direct transfection into dendritic cells. ${ }^{22}$ It was demonstrated that inhibitory effects on the development of allergic inflammation are readily obtained in a mouse model of asthma through the administration of Ag85B DNA, even with only a single administration before or after antigen sensitization.

The mechanism of immune responses induced by Ag85B remains unclear. Various products having adjuvant activities, eg, lipopolysaccharide, cytosine-phosphodiester-guanine motif, and polyinosinic:polycytidylic acid, involve tolllike receptors (TLRs) and show augmentation of Th1-type immune responses. ${ }^{18}$ It was previously reported that plasmid DNA encoding Ag85B stimulated the expression of TLR2, TLR3, and TLR4 mRNA. One possibility is that the induction
A

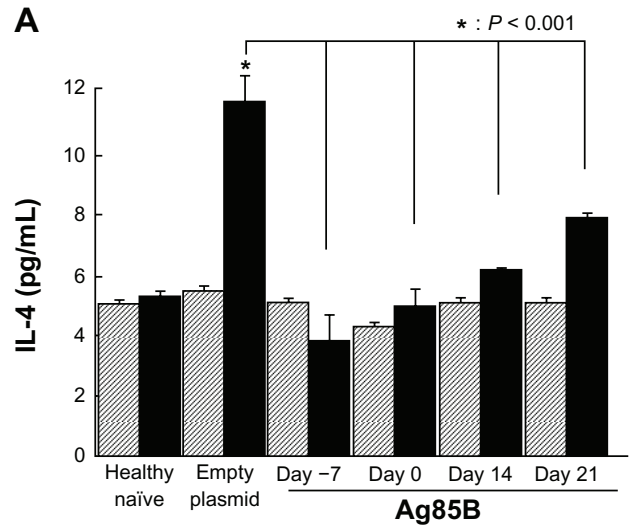

B

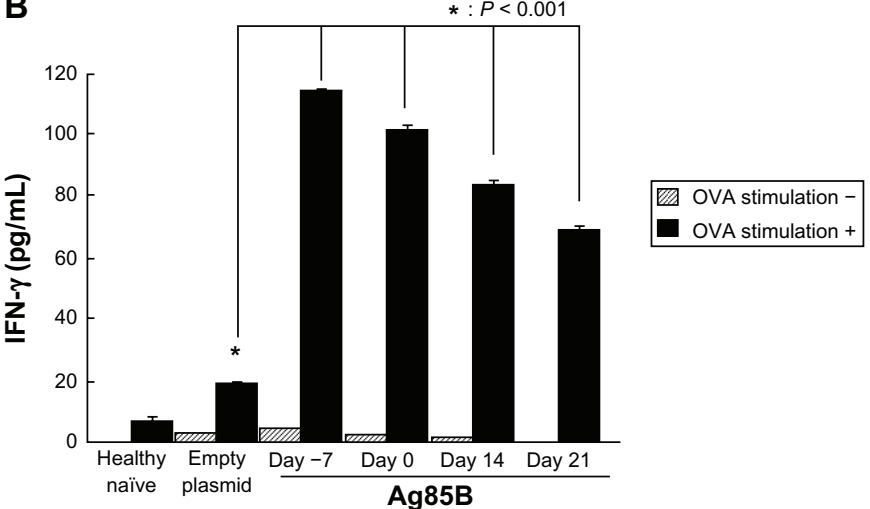

Figure 4 IFN- $\gamma$ and IL-4 production in culture supernatant. Amounts of (A) IFN- $\gamma$ and (B) IL-4 in culture supernatant were measured by enzyme-linked immunosorbent assay 25 days after the first OVA immunization. Spleen cells from immunized mice $\left(5 \times 10^{6}\right)$ were cultured with $10 \mu \mathrm{g} / \mathrm{mL}$ OVA in $24-w e l l$ culture plates at a volume of $2 \mathrm{~mL}$. After incubation at $37^{\circ} \mathrm{C}$ in a humidified incubator ( $5 \%$ carbon dioxide) for 96 hours, culture supernatants were quantified by using a standard enzyme-linked immunosorbent assay kit (Life Technologies, Carlsbad, CA).

Notes: Data are representative of at least three independent experiments; values represent mean and standard deviation of ten mice per group; statistical analysis was performed using the Mann-Whitney $U$ test and the Kruskal-Wallis test.

Abbreviations: Ag85B, antigen 85B; IFN- $\gamma$, interferon- $\gamma$; IL-4, interleukin-4; OVA, ovalbumin. 


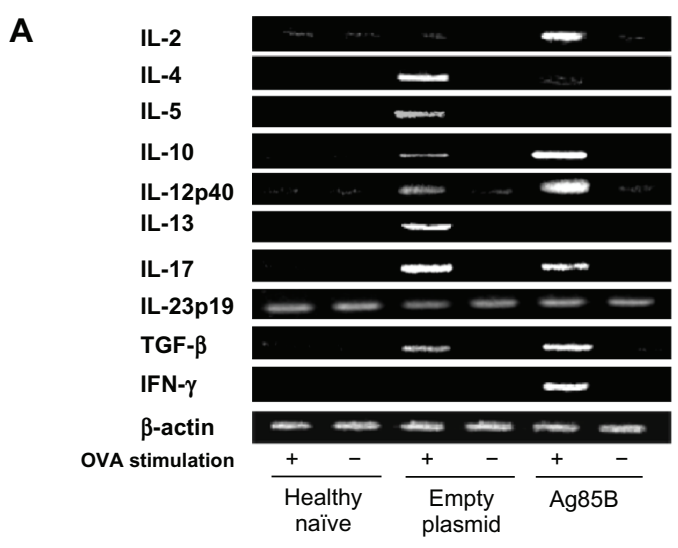

B

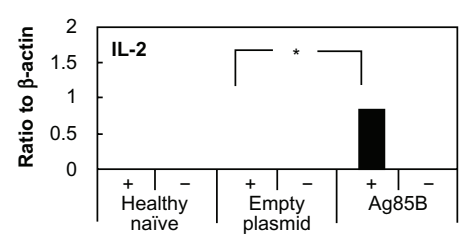

C

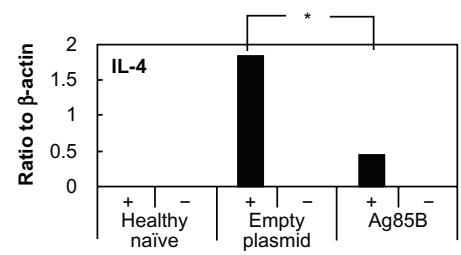

D

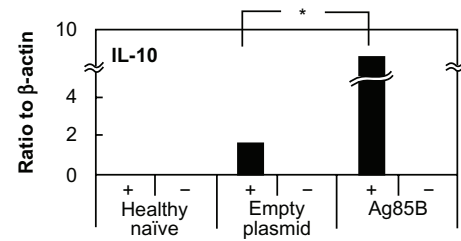

E

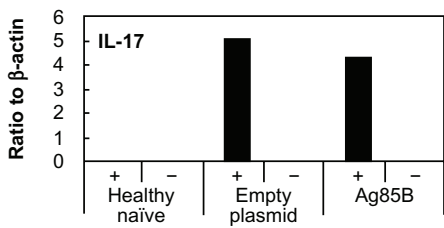

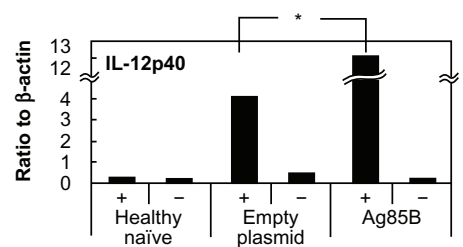
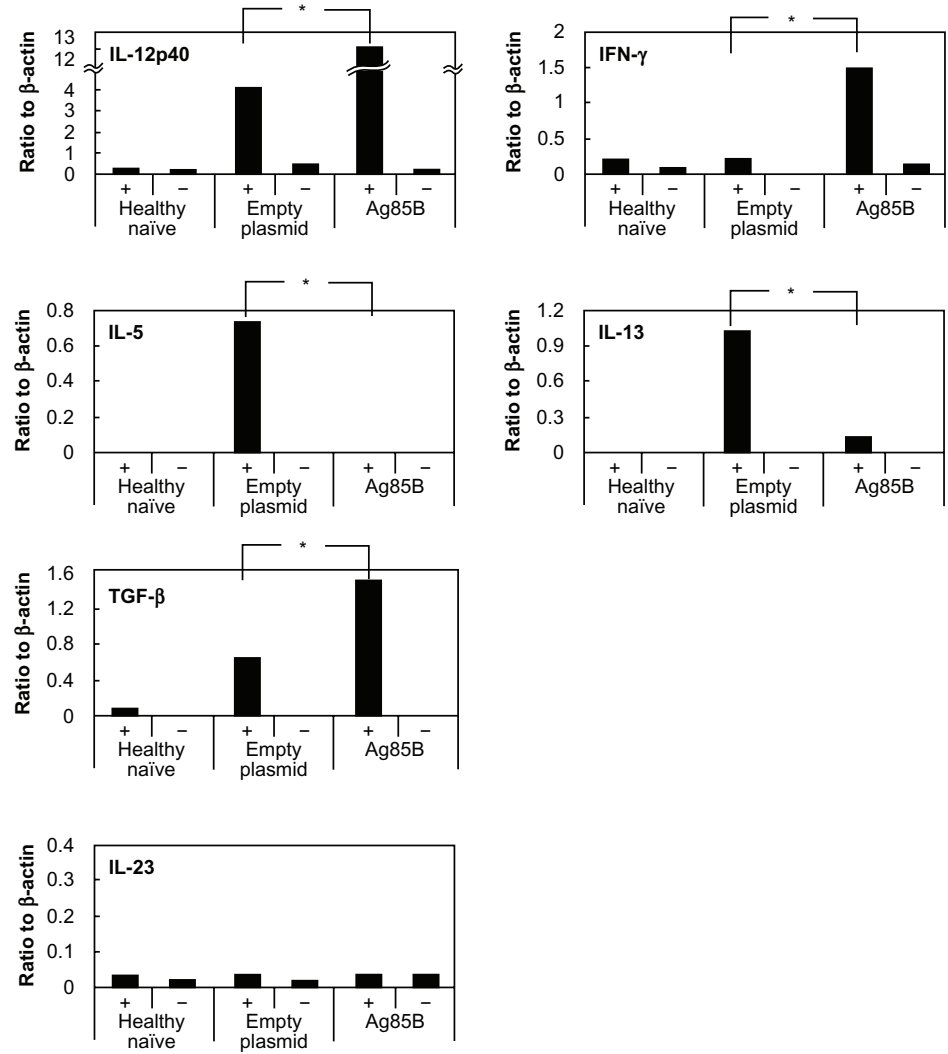

Figure 5 Detection of cytokine messenger ribonucleic acid from lymphocytes using real-time polymerase chain reaction. Spleen cells were stimulated in vitro with OVA for I day in culture. Spleen cells stimulated with fetal calf serum were used as controls. Total ribonucleic acid was purified from the OVA-stimulated or fetal calf serum (control)stimulated spleen cells using Isogen (Nippon Gene Co, Ltd, Tokyo, Japan) following the manufacturer's instructions. For the real-time reaction, a reverse transcription system (Promega Corporation, Fitchburg, WI) was used. Polymerase chain reaction was performed in a total volume of $50 \mu \mathrm{L}$ of I × polymerase chain reaction buffer (Takara Shuzo, Kyoto, Japan) containing 0.5-1.0 $\mu \mathrm{g}$ of complementary DNA, $0.25 \mathrm{mM}$ of each deoxyribonucleotide triphosphate, $2 \mu \mathrm{M}$ of each primer, and $2.5 \mathrm{U}$ of Taq DNA polymerase (Takara Shuzo). The specific primer pairs used were previously described..$^{15}$ The samples were amplified for $30-35$ cycles under the following conditions: annealing for 30 seconds at $56^{\circ} \mathrm{C}$, extension for 1 minute at $73^{\circ} \mathrm{C}$, and denaturation for 30 seconds at $93^{\circ} \mathrm{C}$. (A) The reaction products were analyzed on $2 \%$ agarose, Tris-buffered ethylenediaminetetraacetic acid gels. (B-E) Photographs of the gels were scanned, and band intensities were measured using a densitometer (CS Analyzer 3.0; ATTO Corporation, Tokyo, Japan). The quantity of cytokine messenger ribonucleic acid was determined by the ratio of cytokine and beta actin band intensities.

Notes: $* P<0.005$; the profiles are representative of three independent experiments; statistical analysis was performed using the Mann-Whitney $U$ test and the Kruskal-Wallis test.

Abbreviations: Ag85B, antigen 85B; IFN- $\gamma$, interferon- $\gamma$; IL, interleukin; OVA, ovalbumin; TGF- $\beta$, transforming growth factor- $\beta$.

of Th1-type immune responses by Ag85B is involved in innate immune responses. From this result, the activation of Th1 and Treg cells by Ag85B administration was thought to be involved in responses through stimulation of TLR2, TLR3, and TLR4, but not TLR9. ${ }^{14}$ Various proteins derived from pathogens promote Th1 responses through stimulation of TLRs and subsequently through secretion of cytokines. ${ }^{18}$ It has also been reported that TLR signaling induces not only Th1-type immune responses but also secretion of various cytokines from Treg cells. ${ }^{23-27}$ Moreover, recent studies have 
indicated that Th1 cells produce IL-10 as well as Th1-type cytokines by Notch regulation-dependent signal transducer and activator of transcription-4 signaling. ${ }^{28}$ From these findings, effective immunotherapy by induction of both Th1 cell and Treg cell responses is thought to be possible by using appropriate materials. In fact, an asthma model of mice immunized with culture supernatant of mycobacteria, $M$. vaccae, showed Th1 and Treg responses. ${ }^{16}$ The results of the current study suggest that the administration of Ag85B DNA has several potential advantages due to the activation of Th1 and Treg cells for the prevention and treatment of asthma.

Immunization with mycobacteria or mycobacteria products has been reported to inhibit the development of allergic disease. ${ }^{29-32}$ However, various causative factors affect immune responses by mycobacteria. It was reported as a notable point that the efficacy of mycobacteria in preventing allergic inflammation of asthma was strongly affected by Nramp1 alleles. ${ }^{33}$ Several host genetic factors, including natural resistance-associated macrophage protein 1 (NRAMP1), ${ }^{34}$ vitamin D receptor (VDR), ${ }^{35,36}$ and Mendelian susceptibility to mycobacterial disease, ${ }^{37}$ have been reported to be involved in responses to mycobacteria (reviewed in Casanova and Abel). ${ }^{38}$ Differences in immune responses induced by different mycobacteria strains have also been reported. The differential immune responses were mediated by lipid-extracted molecules of mycobacteria. ${ }^{39}$ Moreover, environmental factors are important for immune responses induced by mycobacteria in therapy for atopic diseases. ${ }^{40,41}$ Presensitization of mycobacteria in the natural environment affects the induction of Th1-type immune responses by mycobacteria vaccination. ${ }^{9,42,43}$ However, the specific components of mycobacteria that inhibit the development of allergic responses have not been reported. Ag85B is a single component of mycobacteria, and this product might not be affected by various other mycobacteria factors involved in immune responses. In fact, Th1-type immune responses induced by Ag85B are not affected by Nramp in mice..$^{44,45}$

Wu et al demonstrated the effects of intranasal administration of Ag85B in a mouse model of asthma. ${ }^{46}$ It was previously reported that $\mathrm{Ag} 85 \mathrm{~B}$ has strong adjuvant activities involving Th1 immune responses. ${ }^{14}$ Intranasal administration of a plasmid DNA (DNA vaccine) with adjuvant activities has been considered to be inappropriate for human use. Intranasal inactivated influenza vaccine, with adjuvant, induced Bell's palsy in humans. Therefore, intranasal inactivated influenza vaccine with adjuvant is no longer in clinical use. ${ }^{47}$ Systemic administration of a plasmid DNA (DNA vaccine) is better than intranasal administration if the same effects of the plasmid
DNA can be induced. The current study demonstrated the usefulness of Ag85B DNA vaccine and provided evidence of the potential utility of Ag85B DNA vaccine for the prevention and treatment of asthma, even with only a single systemic administration before or after antigen sensitization.

\section{Conclusion}

The correction of immune response should be considered in the prevention and treatment of asthma. Ag85B has potential utility for the prevention and treatment of asthma even with only a single administration.

\section{Acknowledgments}

This work was supported by Health Science Research Grants from the Ministry of Health, Labor, and Welfare of Japan and the Ministry of Education, Culture, Sports, Science, and Technology of Japan.

\section{Disclosure}

The authors report no conflicts of interest in this work.

\section{References}

1. Umetsu DT, DeKruyff RH. TH1 and TH2 CD4+ cells in human allergic diseases. J Allergy Clin Immunol. 1997;100(1):1-6.

2. Wills-Karp M, Luyimbazi J, Xu X, et al. Interleukin-13: central mediator of allergic asthma. Science. 1998;282(5397):2258-2261.

3. Lambrecht $\mathrm{BN}$, Hammad $\mathrm{H}$. The airway epithelium in asthma. Nat Med. 2012;18(5):684-692.

4. Bentley AM, Meng Q, Robinson DS, Hamid Q, Kay AB, Durham SR. Increases in activated $\mathrm{T}$ lymphocytes, eosinophils, and cytokine mRNA expression for interleukin-5 and granulocyte/macrophage colony-stimulating factor in bronchial biopsies after allergen inhalation challenge in atopic asthmatics. Am J Respir Cell Mol Biol. 1993;8(1): 35-42.

5. Bossley CJ, Fleming L, Gupta A, et al. Pediatric severe asthma is characterized by eosinophilia and remodeling without $\mathrm{T}(\mathrm{H}) 2$ cytokines. J Allergy Clin Immunol. 2012;129(4):974-982.e13.

6. Akdis CA, Akdis M. Mechanisms and treatment of allergic disease in the big picture of regulatory T cells. J Allergy Clin Immunol. 2009;123(4): 735-746.

7. Hawrylowicz CM, O'Garra A. Potential role of interleukin-10-secreting regulatory T cells in allergy and asthma. Nat Rev Immunol. 2005;5(4): 271-283.

8. Racila DM, Kline JN. Perspectives in asthma: molecular use of microbial products in asthma prevention and treatment. J Allergy Clin Immunol. 2005;116(6):1202-1205.

9. Krishna MT, Salvi SS. Could administration of bacille Calmette-Guerin vaccination at birth protect from the development of asthma and allergic diseases in the western world? Has this question been adequately investigated? Pediatr Allergy Immunol. 2002;13(3):172-176.

10. Harada M, Magara-Koyanagi K, Watarai H, et al. IL-21-induced Bepsilon cell apoptosis mediated by natural killer T cells suppresses IgE responses. J Exp Med. 2006;203(13):2929-2937.

11. Arnoldussen DL, Linehan M, Sheikh A. BCG vaccination and allergy: a systematic review and meta-analysis. J Allergy Clin Immunol. 2011; 127(1):246-253.

12. Tamura $\mathrm{T}$, Ariga $\mathrm{H}$, Kinashi $\mathrm{T}$, et al. The role of antigenic peptide in $\mathrm{CD} 4+\mathrm{T}$ helper phenotype development in a $\mathrm{T}$ cell receptor transgenic model. Int Immunol. 2004;16(12):1691-1699. 
13. Kuromatsu I, Matsuo K, Takamura S, et al. Induction of effective antitumor immune responses in a mouse bladder tumor model by using DNA of an alpha antigen from mycobacteria. Cancer Gene Ther. 2001;8(7): 483-490.

14. Takamura S, Matsuo K, Takebe Y, Yasutomi Y. Ag85B of mycobacteria elicits effective CTL responses through activation of robust Th1 immunity as a novel adjuvant in DNA vaccine. J Immunol. 2005;175(4): 2541-2547.

15. Nishikubo K, Murata Y, Tamaki S, et al. A single administration of interleukin-4 antagonistic mutant DNA inhibits allergic airway inflammation in a mouse model of asthma. Gene Ther. 2003;10(26): 2119-2125.

16. Zuany-Amorim C, Sawicka E, Manlius C, et al. Suppression of airway eosinophilia by killed Mycobacterium vaccae-induced allergen-specific regulatory T-cells. Nat Med. 2002;8(6):625-629.

17. Korn T, Bettelli E, Oukka M, Kuchroo VK. IL-17 and Th17 cells. Annu Rev Immunol. 2009;27:485-517.

18. Takeda K, Kaisho T, Akira S. Toll-like receptors. Annu Rev Immunol. 2003;21:335-376.

19. Tuting T, Storkus WJ, Falo LD Jr. DNA immunization targeting the skin: molecular control of adaptive immunity. J Invest Dermatol. 1998; 111(2):183-188.

20. Condon C, Watkins SC, Celluzzi CM, Thompson K, Falo LD Jr. DNA-based immunization by in vivo transfection of dendritic cells Nat Med. 1996;2(10):1122-1128.

21. Porgador A, Irvine KR, Iwasaki A, Barber BH, Restifo NP, Germain RN. Predominant role for directly transfected dendritic cells in antigen presentation to CD8+ T cells after gene gun immunization. J Exp Med. 1998;188(6):1075-1082.

22. Tajiri K, Imanaka-Yoshida K, Matsubara A, et al. Suppressor of cytokine signaling 1 DNA administration inhibits inflammatory and pathogenic responses in autoimmune myocarditis. J Immunol. 2012;189(4): 2043-2053.

23. Lloyd CM, Hawrylowicz CM. Regulatory T cells in asthma. Immunity. 2009;31(3):438-449.

24. Jin B, Shun T, Yu XH, Yang YX, Yeo AE. The effects of TLR activation on T-cell development and differentiation. Clin Dev Immunol. 2012; 2012:836485.

25. Ouabed A, Hubert FX, Chabannes D, Gautreau L, Heslan M, Josien R. Differential control of $\mathrm{T}$ regulatory cell proliferation and suppressive activity by mature plasmacytoid versus conventional spleen dendritic cells. J Immunol. 2008;180(9):5862-5870.

26. Jarnicki AG, Conroy $\mathrm{H}$, Brereton $\mathrm{C}$, et al. Attenuating regulatory $\mathrm{T}$ cell induction by TLR agonists through inhibition of $\mathrm{p} 38$ MAPK signaling in dendritic cells enhances their efficacy as vaccine adjuvants and cancer immunotherapeutics. J Immunol. 2008;180(6): 3797-3806.

27. Bell MP, Svingen PA, Rahman MK, Xiong Y, Faubion WA Jr. FOXP3 regulates TLR10 expression in human T regulatory cells. J Immunol. 2007;179(3):1893-1900.

28. Rutz S, Janke M, Kassner N, Hohnstein T, Krueger M, Scheffold A. Notch regulates IL-10 production by T helper 1 cells. Proc Natl Acad Sci USA. 2008;105(9):3497-3502.

29. Herz U, Gerhold K, Gruber C, et al. BCG infection suppresses allergic sensitization and development of increased airway reactivity in an animal model. J Allergy Clin Immunol. 1998;102(5):867-874.
30. Wang CC, Rook GA. Inhibition of an established allergic response to ovalbumin in BALB/c mice by killed Mycobacterium vaccae. Immunology. 1998;93(3):307-313.

31. Yang X, Wang S, Fan Y, Zhu L. Systemic mycobacterial infection inhibits antigen-specific immunoglobulin E production, bronchial mucus production and eosinophilic inflammation induced by allergen. Immunology. 1999;98(3):329-337.

32. Cavallo GP, Elia M, Giordano D, Baldi C, Cammarota R. Decrease of specific and total IgE levels in allergic patients after BCG vaccination: preliminary report. Arch Otolaryngol Head Neck Surg. 2002;128(9): 1058-1060.

33. Bellamy R. Susceptibility to mycobacterial infections: the importance of host genetics. Genes Immun. 2003;4(1):4-11.

34. Smit JJ, Van Loveren H, Hoekstra MO, Karimi K, Folkerts G, Nijkamp FP. The Slc11a1 (Nramp1) gene controls efficacy of mycobacterial treatment of allergic asthma. J Immunol. 2003;171(2): 754-760.

35. Bellamy R, Ruwende C, Corrah T, et al. Tuberculosis and chronic hepatitis $\mathrm{B}$ virus infection in Africans and variation in the vitamin $\mathrm{D}$ receptor gene. J Infect Dis. 1999;179(3):721-724.

36. Yang HF, Zhang ZH, Chang ZQ, Tang KL, Lin DZ, Xu JZ. Vitamin D deficiency affects the immunity against Mycobacterium tuberculosis infection in mice. Clin Exp Med. August 10, 2012. [Epub ahead of print.]

37. Reichenbach J, Rosenzweig S, Doffinger R, Dupuis S, Holland SM, Casanova JL. Mycobacterial diseases in primary immunodeficiencies. Curr Opin Allergy Clin Immunol. 2001;1(6):503-511.

38. Casanova JL, Abel L. Genetic dissection of immunity to mycobacteria: the human model. Annu Rev Immunol. 2002;20:581-620.

39. Manca C, Reed MB, Freeman S, et al. Differential monocyte activation underlies strain-specific Mycobacterium tuberculosis pathogenesis. Infect Immun. 2004;72(9):5511-5514.

40. Arkwright PD, David TJ. Effect of Mycobacterium vaccae on atopic dermatitis in children of different ages. Br J Dermatol. 2003;149(5): 1029-1034.

41. Arkwright PD, David TJ. Intradermal administration of a killed Mycobacterium vaccae suspension (SRL 172) is associated with improvement in atopic dermatitis in children with moderate-to-severe disease. J Allergy Clin Immunol. 2001;107(3):531-534.

42. Martignon G, Oryszczyn MP, Annesi-Maesano I. Does childhood immunization against infectious diseases protect from the development of atopic disease? Pediatr Allergy Immunol. 2005;16(3):193-200.

43. Choi IS, Koh YI. Effects of BCG revaccination on asthma. Allergy. 2003;58(11):1114-1116.

44. Lozes E, Huygen K, Content J, et al. Immunogenicity and efficacy of a tuberculosis DNA vaccine encoding the components of the secreted antigen 85 complex. Vaccine. 1997;15(8):830-833.

45. Baldwin SL, D’Souza CD, Orme IM, et al. Immunogenicity and protective efficacy of DNA vaccines encoding secreted and non-secreted forms of Mycobacterium tuberculosis Ag85A. Tuber Lung Dis. 1999; 79(4):251-259.

46. Wu J, Xu J, Cai C, Gao X, Li L, Zhong N. Ag85B DNA vaccine suppresses airway inflammation in a murine model of asthma. Respir Res. 2009;10:51.

47. Mutsch M, Zhou W, Rhodes P, et al. Use of the inactivated intranasal influenza vaccine and the risk of Bell's palsy in Switzerland. $N$ Engl J Med. 2004;350(9):896-903.

Journal of Asthma and Allergy

\section{Publish your work in this journal}

The Journal of Asthma and Allergy is an international, peer-reviewed open-access journal publishing original research, reports, editorials and commentaries on the following topics: Asthma; Pulmonary physiology; Asthma related clinical health; Clinical immunology and the immunological basis of disease; Pharmacological interventions and

new therapies. Issues of patient safety and quality of care will also be considered. The manuscript management system is completely online and includes a very quick and fair peer-review system, which is all easy to use. Visit http://www.dovepress.com/testimonials.php to read real quotes from published authors. 